\title{
Contribution of piezometric measurement to knowledge and management of low water levels: examples on the chalk aquifer in the Champagne Ardennes region
}

\author{
P. STOLLSTEINER ${ }^{1}$, H. BESSIERE ${ }^{1}$, J. NICOLAS ${ }^{1}$, D. ALLIER ${ }^{1}$ \& O. BERTHET ${ }^{\mathbf{2}}$ \\ 1 BRGM, Water, Environment and Ecotechnologies division, Orléans, France \\ p.stollsteiner@brgm.fr \\ 2 DREAL Champagne-Ardenne, Natural Resource Service, Water Resources Pole
}

This article is based on a BRGM study on piezometric indicators, threshold values of discharge and groundwater levels for the assessment of potentially-exploitable water resources of chalky watersheds.

A method for estimating low water levels based on groundwater levels is presented from three examples representing chalk aquifers with different cycles: annual, combined and interannual. The first is located in Picardy and the two others in the Champagne-Ardennes region. Piezometers with annual cycles, used in these examples, are supposed to be representative of the aquifer hydrodynamics. Except for multi-annual systems, the analysis between discharge measurements at a hydrometric station and groundwater levels measured at a piezometer representative of the main aquifer, leads to relatively precise and satisfactory relationships within a chalky context. These relationships may be useful for monitoring, validation, extension or reconstruction of the low water flow data. On the one hand, they allow definition of the piezometric levels corresponding to the different alert thresholds of river discharges. On the other hand, they clarify the proportions of low surface water flow from runoff or drainage of the aquifer. Finally, these correlations give an assessment of the minimum flow for the coming weeks.

However, these correlations cannot be used to optimize the value of the exploitable water resource because it seems to be difficult to integrate the value of the effective rainfall that could occur during the draining period. Moreover, in the case of multi-annual systems, the solution is to attempt a comprehensive system modelling and, if it is satisfactory, using the simulated values to get rid of parasites or running the model for forecasting purposes.

\section{REFERENCES}

Stollsteiner, P. et al. (2013) Congrès SHF: Hydrométrie 2013, Paris, 15-16 mai 2013.

Stollsteiner, P. et al. (2014) Poster presentation, European Geosciences Union General Assembly 2014, Vienna, Austria, 27 April-2 May 2014. 